\title{
Activation or suppression of the immune response mediators in biliary tract cancer (BTC) patients: a systematic review and meta-analysis
}

\author{
Ying Wang1 ${ }^{*}$, Min Ding5*, Qian Zhang2 ${ }^{*}$, Jinghan Wang6, Xijing Yang2, Fuping Zhou ${ }^{2}$, Linfang Li1, \\ Zhengang Yuan ${ }^{2}$, Huajun Jin ${ }^{1,3}$, Qijun Qian ${ }^{1,2,3,4} \bowtie$ \\ 1. Laboratory of Gene and Viral Therapy, Eastern Hepatobiliary Surgery Hospital, the Second Military Medical University of Chinese PLA, Shanghai, China. \\ 2. Department of Biotherapy, Eastern Hepatobiliary Surgery Hospital, the Second Military Medical University of Chinese PLA, Shanghai, China. \\ 3. Shanghai Cell Therapy Research Institute, Shanghai, China. \\ 4. Ningbo No.5 Hospital (Ningbo Cancer Hospital), Ningbo, China. \\ 5. Department of Tumor Interventional Oncology, Renji Hospital, School of Medicine, Shanghai Jiaotong University, Shanghai, China. \\ 6. Department of Biliary Surgery, Eastern Hepatobiliary Surgery Hospital, the Second Military Medical University of Chinese PLA, Shanghai, China. \\ *These authors contributed equally to this work. \\ $\square$ Corresponding author: Email: qianqj@sino-gene.cn. \\ (c) Ivyspring International Publisher. This is an open access article distributed under the terms of the Creative Commons Attribution (CC BY-NC) license \\ (https:// creativecommons.org/licenses/by-nc/4.0/). See http://ivyspring.com/terms for full terms and conditions.
}

Received: 2016.08.07; Accepted: 2016.09.18; Published: 2017.01.01

\begin{abstract}
Background: Infiltration of immune cells and immune microenvironment determine the proliferative activity of the tumor and metastasis. The aim of this study was to analyze the influence of activation or suppression of the immune response mediators on the prognosis of biliary tract cancer (BTC).

Methods: We searched Pubmed, Web of Science, Embase and The Cochrane Library for relevant literatures until June 2016. The quality of studies was assessed by QUADAS-2 and NOS tools. Forest and funnel plots and all statistical analyses were generated by using Review Manager 5.3. The bias of included studies was estimated by Egger's test using Meta $R$ package.

Results: A total of 2339 patients from 12 studies were finally enrolled in this meta-analysis. Patients with high expression of immune active factors, intraepithelial tumor-infiltrating CD4+ , CD8+, and Foxp3+ T lymphocytes, MHC I, NKG2D, showed a better overall survival (OS) than those with low expression $(\mathrm{HR}=0.52,95 \% \mathrm{Cl}=0.41-0.67, \mathrm{P}<0.00001)$. On the contrary, the high expression of immune suppressive factors (CD66b+ neutrophils, Neutrophil-lymphocyte ratio, Intratumoral IL-17+ cells and PD-1+/CD8+ TILs) was significantly associated with poor OS $(\mathrm{HR}=1.79,95 \% \mathrm{Cl}=1.44-2.22, \mathrm{P}<0.00001)$. A further analysis of therapies targeting tumor microenvironment modulation showed that the median progression free survival (PFS) for BTC patients who received adjuvant immunotherapy was longer than those who received surgery or chemotherapy alone, and the estimated pooled mean difference demonstrated a highly significant improvement ( $\mathrm{MD}=2.33 ; 95 \% \mathrm{Cl}: 0.63-4.02, \mathrm{P}=0.007)$. The total effect of PFS and OS was statistically longer in experimental group, compared to patients in control groups, respectively (PFS: $R R=1.25$; 95\% Cl: 1.08-1.46, $P=0.004$; OS: $R R=1.16$; $95 \% \mathrm{Cl}$ : 1.07-1.27, $\mathrm{P}=0.0006$ ). In subgroup meta-analysis of studies on 6-, 12- and 18-month PFS and OS, it showed that adjuvant immunotherapy could improve the 6-month PFS (RR=1.23; 95\% Cl: 1.05-1.44, $\mathrm{P}=0.009)$, and 6-month OS (RR=1.17; 95\% Cl: 1.06-1.30, $\mathrm{P}=0.002)$.
\end{abstract}

Conclusions: So given the above issue, our meta-analysis confirmed that the level of immune mediators could be a predicative factor for prognosis of BTC patients, and immunotherapy regimens by modulating the tumor microenvironment was superior for enhancing median PFS, 6-month PFS and OS.

Key words: biliary tract cancer; immune response mediators; immunotherapy; meta-analysis. 


\section{Introduction}

Biliary tract cancer (BTC) is an aggressive malignancy arising from a heterogeneous group of neoplasms of the biliary tract, including intrahepatic cholangiocarcinoma, hilar-cholangiocarcinoma, extrahepatic cholangiocarcinoma, gallbladder carcinoma and ampullary carcinoma [1, 2]. The annual incidence and mortality of BTC is increasing worldwide [3], with the highest rates in Asia countries and Latin America [4]. Unfortunately, the prognosis of BTC is dismal. The 5-year survival rate of patients with BTC is only at $5 \%$ to $40 \%$ due to high recurrence and metastases. The median survival from time of diagnosis is less than 9 months [5].

Surgery, chemotherapy and radiation, currently, are the common treatment modalities for BTC. Surgical resection offers the only potential chance of cure for BTC, however, the majority of cases present as unresectable disease due to the difficulty in obtaining an early diagnosis [6]. Hence, patients with non-operation are generally treated with chemotherapy with or without radiotherapy. Even for patients after surgical resection, adjuvant chemotherapy or radiation therapy is still required in many cases in order to improve the cure. It is a fact that the roles in adjuvant therapeutic regimens have not been established yet. The clinical outcomes of BTC are generally poor, especially for unresectable cases, with the median survival time only 6 months [7]. Therefore, the new modalities of therapeutic strategies for BTC are highly demanded.

Tumor cells are often surrounded by infiltrating immune cells. Immune microenvironment determines the proliferative activity of the tumor cells, invasion and metastasis. In BTC, several immune mediators have so far been investigated [8-14]. Studies identified immune cell types or ratio including CD4+, CD8+, and Foxp3+ Tumor-infiltrating T lymphocytes (TILs), IL17+, neutrophil recruitment (CD66b+), PD-1/CD8 TILs and neutrophil/lymphocyte (NLR), and analyzed the distribution and clinical relevance of these mediators $[8,10,12-14]$. Others observed the impact of the expression of major histocompatibility complex class I (MHC I) and natural killer group 2 member D (NKG2D) $[9,11]$.

The immune microenvironment has been clarified their tumor-infiltrating immune cells types that intimately influence the outcome of BTC. Immunotherapy, containing passive immunotherapy and active immunotherapy, has emerged as a promising treatment for many malignant diseases in recent decades. For the treatment of BTC, it has also evolved into early clinical studies with encouraging preliminary curative effect [15]. Passive immunotherapy, monoclonal antibodies targeting epidermal growth factor receptor (EGFR) and vascular endothelial growth factor (VEGF), has been reported to enhance the therapeutic effects of BTC [16]. Adjuvant treatments, such as chemotherapies combined with cetuximab (EGFR inhibitor), Erlotinib (tyrosine-kinase inhibitor of EGFR) or bevacizumab (VEGF inhibitor), have also been explored [17-20]. David Malka [17] designed a randomized, open-label, non-comparative phase 2 trial to assess the efficacy Gemcitabine and oxaliplatin with or without cetuximab in advanced BTC. Both J.S Chen [18] and Seung Tae Kim [20] have reported a randomized and large-scale advanced BTC trial on the therapeutic effect of anti-EGFR agents (cetuximab in combination with GEMOX). Jeeyun Lee [21] designed a randomized phase 3 trial in patients with advanced BTC after treatment with gemcitabine and oxaliplatin plus erlotinib. As for active immunotherapy, using dendritic cell-based vaccine plus activated $\mathrm{T}$ cell transfer has also emerged as a potential therapy strategy for BTC. Various approaches for therapeutic immunotherapy in BTC [22], including MUC1 peptide, MUC1 peptide-loaded DCs, WT1 peptide, Tumor lysatepulsed DCs plus activated T cell transfer and personalized peptide vaccine (PPV), have been applied and clinically reported with promising results. Koichi Shimizu [23] administered an autologous dendritic cell vaccine plus activated T-cell transfer in patients with advanced gastrointestinal cancers.

Herein, we conducted a systematic meta-analysis to assess the effect of activation or suppression of the immune mediators on the prognosis of BTC, and further summarized the trials of immunotherapy regimens by modulating the tumor microenvironment for BTC patients.

\section{Materials and methods}

\section{Search strategy}

Relevant studies were performed by Pubmed, Web of Science, Embase and The Cochrane Library. The current search was updated to June 2016 using combinations of the following keywords: [biliary tract cancer OR cholangiocarcinoma OR bile duct cancer OR ampullary carcinomas OR gallbladder cancer] AND [prognos* OR factor OR mediator] AND [immunotherapy OR cytokine induced killer cell OR tumor infiltrating lymphocyte $\mathrm{OR}$ cytotoxic $\mathrm{T}$ lymphocyte OR adoptive cell therapy OR adoptive immunotherapy OR CIK OR LAK OR DC OR NK OR TIL]. Studies were not limited to language.

\section{Inclusion and exclusion criteria}

Literatures that met the following criteria were included in this meta-analysis: (i) reported clinical 
outcomes of immunotherapy or assessed prognostic impact of immune cells/factors; (ii) the case-control study designs; (iii) provided enough information. Studies where raw data was unavailable, incomplete, or the number of enrolled patients less than 15 were excluded.

\section{Data extraction and quality assessment}

All candidate literatures were evaluated and extracted by two independent authors (Ying Wang and Min Ding). If disagreement occurred, two authors discussed and arrived at consensus with other authors. For each study, the following information was extracted from included studies: authors, year of publication, tumor characteristics, number of patients, regimen used or immune factors, median time of overall survival and progression-free survival. To assess the quality, both the risk of bias and applicability of a study were analyzed. We used the Quality Assessment of Diagnostic Accuracy Studies-2 (QUADAS-2) tool for randomized trials studies [24]. The QUADAS-2 contained four key domains covering patient selection, index test, reference standard, and flow and timing. The "low risk of bias", "unclear risk of bias" or "high risk of bias" was applied to assess risk of bias in Cochrane reviews of interventions. Additionally, the quality of the non-randomized studies was estimated by utilizing the Newcastle Ottawa quality assessment scale (NOS) [25]. The quality was evaluated by three items: patient selection, comparability of groups and the assessment of outcomes. Studies were graded on an ordinal star scoring scale with high scores representing high quality. The score is ranged from zero stars (worst) to eight stars (best). One study was assigned as the credible one with good methodological quality when it equals to or greater than six stars generally.

\section{Statistical methods}

For the median progression free survival (PFS) and overall survival (OS) meta-analysis, a random effects model (the Inverse Variance statistical method) was performed, and the statistical analyses were conducted by using pair-wise comparison of the experimental arms with the control arms. Treatment effects are reflected by mean difference (MD) for median PFS and OS in this model. Likewise, treatment effects are reflected by risk ratio (RR) for PFS and OS. The number of events evaluated in each arm was utilized to calculate the pooled RR with 95\% confidence intervals (CI) combined the Mantel-Haenszel statistical method with random effects. A pooled hazard ratio (HR) and $95 \% \mathrm{CI}$ were calculated for immune factors using a random effects model and the Inverse Variance statistical method.
The Cochran's $Q$ test (chisquared test; $\mathrm{x}^{2}$ ) was applied to evaluate whether the results of the studies were homogeneous. All the heterogeneity was quantified by inconsistency index $\left(\mathrm{I}^{2}\right)$ with $25 \%, 50 \%$, and $75 \%$ representing the evidence of low, moderate, and high heterogeneity, respectively. A p-value of below 0.05 is considered to be statistically significant. Forest plots and funnel plots and all statistical analyses above were generated by using Review Manager 5.3 [26]. Publication bias was assessed with Egger's test using Meta R package.

\section{Results}

\section{Selection of the trials}

A search of Pubmed, Web of science, Embase and The Cochrane Library identified a total of 833 citations, of which 87 were excluded as they were duplicates (Figure 1). After title and abstract review, 687 studies were excluded for various reasons (77 were reviews, 70 were in vitro experiments, 43 used animal models, 46 was one case report, 13 were conference abstracts, 154 studied other diseases, 221 used other treatments and 63 had no relation to curative effect). The full texts of the remaining 59 articles were assessed for eligibility and were retrieved for a more detailed assessment. We filtered a total of 47 of these studies without a control group or completed patient clinical data. An overview of this process was shown in Figure 1. As a result, 12 of studies included in quantitative synthesis were selected for meta-analysis.

The characteristics of the populations presented in these reports were summarized in Table 1 . The 12 included papers comprised 4 randomized clinical studies, 8 prospective studies with a matched-pair control group (non-randomized studies). The sources of articles were from the Japan (three trials), Korea (four trials), China (two trials) and Germany (two trials), and one trial was enrolled in the study across France and Germany. Tumor characteristics were reported in all studies.

\section{Quality assessment}

In 12 selected studies, the effect of regiments was estimated in five studies. The five articles contained four with all low risk of bias and the left one with unclear risk of selection, performance and detection bias (Table 2). The prognostic effect of immune factors was evaluated in the other seven studies. As is shown in Table 3, two out of seven studies included multiple hospitals cases. The NOS score indicated that all seven researches were classified as "high" quality studies with equal to or greater than six stars. 


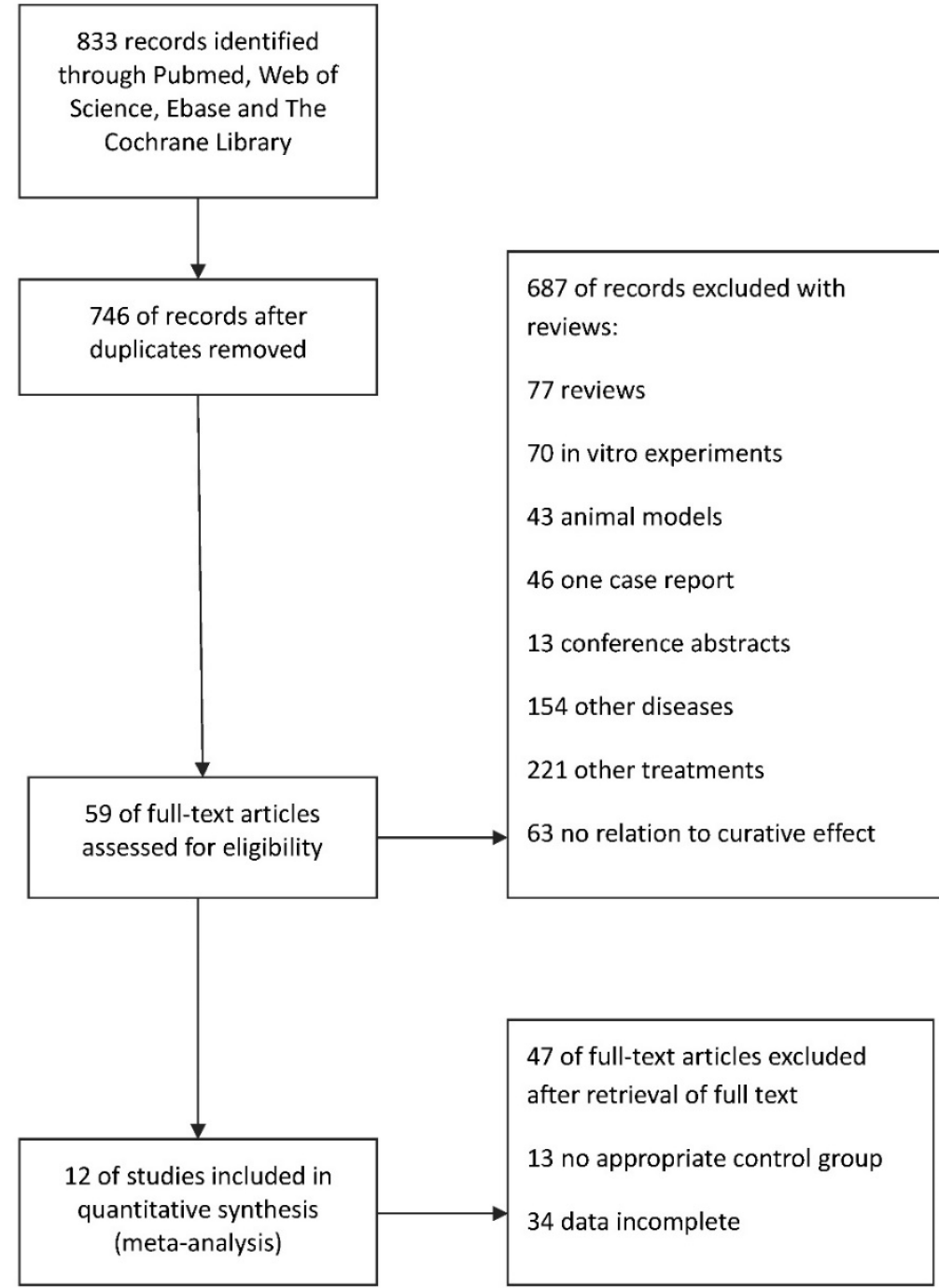

Figure 1. A flow diagram of literature search and study selection. A flowchart of the literature search has been performed. Among 833 screened citations from 4 databases, we identified twelve eligible studies with a total of 2339 participants.

Table 1. The characteristics of the populations.

\begin{tabular}{|c|c|c|c|c|c|c|c|}
\hline \multicolumn{8}{|c|}{ Clinical information of the 5 trials for the regimens } \\
\hline Reference & $\begin{array}{l}\text { Tumor } \\
\text { characteristics }\end{array}$ & $\begin{array}{l}\text { Number of } \\
\text { patient(control) }\end{array}$ & $\begin{array}{l}\text { Median OS of } \\
\text { patient(control) }\end{array}$ & $\begin{array}{l}\text { Median PFS of } \\
\text { patient(control) }\end{array}$ & Regimens & & Course \\
\hline $\begin{array}{l}\text { J. S. Chen } \\
2015^{18}\end{array}$ & $\mathrm{ICC} / \mathrm{ECC}+\mathrm{GBC}$ & $62(60)$ & 10.6(9.8) months & $6.7(4.1)$ months & $\begin{array}{l}\text { Chemo+ } \\
\text { cetuximab }\end{array}$ & $\begin{array}{l}500 \mathrm{mg} / \mathrm{m} 2 \\
\text { cetuximab }\end{array}$ & $\begin{array}{l}1 \text { time/ } 2 \text { weeks until } \\
\text { disease progression }\end{array}$ \\
\hline $\begin{array}{l}\text { David Malka } \\
2014^{17}\end{array}$ & BTC & $76(74)$ & 11(12.4) months & 6.1(4.0) months & $\begin{array}{l}\text { Chemo+ } \\
\text { cetuximab }\end{array}$ & $\begin{array}{l}500 \mathrm{mg} / \mathrm{m} 2 \text { as a } \\
150 \mathrm{~min} \\
\text { intravenous } \\
\text { infusion }\end{array}$ & $\begin{array}{l}1 \text { time/ } 2 \text { weeks until } \\
\text { disease progression }\end{array}$ \\
\hline $\begin{array}{l}\text { Koichi Shimizu } \\
2012^{23}\end{array}$ & ICC & $36(26)$ & 31.9(17.4) months & 18.3(7.7) months & $\begin{array}{l}\text { Surgery+ } \\
\text { DC-CAT cells }\end{array}$ & $\begin{array}{l}\text { Postoperative } \\
\text { adjuvant } \\
\text { immunotherapy }\end{array}$ & Three at 2 months \\
\hline $\begin{array}{l}\text { Jeeyun Lee } \\
2012^{21}\end{array}$ & BTC & 135(133) & 9.5(9.5) months & 5.8(4.2) months & $\begin{array}{l}\text { Chemo+ } \\
\text { Erlotinib }\end{array}$ & $100 \mathrm{mg}$ daily & $\begin{array}{l}1 \text { time/ } 2 \text { weeks until } \\
\text { disease }\end{array}$ \\
\hline $\begin{array}{l}\text { Seung Tae Kim } \\
2015^{20}\end{array}$ & BTC & $54(49)$ & 11.4(9.5)months & 8.3(5.4)months & $\begin{array}{l}\text { Chemo+ } \\
\text { Erlotinib }\end{array}$ & 100 mg daily & $\begin{array}{l}1 \text { time/ } 2 \text { weeks until } \\
\text { disease }\end{array}$ \\
\hline \multicolumn{8}{|c|}{ Clinical information of the 7 trials for the immune prognostic factors } \\
\hline Reference & $\begin{array}{l}\text { Tumor } \\
\text { characteristics }\end{array}$ & \multicolumn{3}{|l|}{ Source } & Period & Treatment & Factors \\
\hline $\begin{array}{l}\text { Ban Seok Lee } \\
2016^{14}\end{array}$ & CCA & \multicolumn{3}{|c|}{$\begin{array}{l}\text { Seoul National University } \\
\text { Hospital }\end{array}$} & 2004-2013 & $\begin{array}{l}\text { systemic } \\
\text { chemotherapy }\end{array}$ & $\begin{array}{l}\text { Neutrophil-lymphocyte } \\
\text { ratio }\end{array}$ \\
\hline $\begin{array}{l}\text { Mariko Tsukagoshi } \\
2016^{11}\end{array}$ & ECC & \multicolumn{3}{|c|}{$\begin{array}{l}\text { Gunma University Hospital (Maebashi, Japan) or } \\
\text { Saiseikai Maebashi Hospital (Maebashi, Japan) }\end{array}$} & $1995-2010$ & surgery & NKG2D \\
\hline
\end{tabular}




\begin{tabular}{|c|c|c|c|c|c|}
\hline $\begin{array}{l}\text { Benjamin Goeppert } \\
2015^{9}\end{array}$ & BTC & The University Hospital Heidelberg & $1995-2010$ & surgery & MHC I \\
\hline $\begin{array}{l}\text { Yu Jin Lim } \\
2015^{13}\end{array}$ & EHBD & $\begin{array}{l}\text { Seoul National University College of Medicine and } \\
\text { Medical Research Center, Seoul National University }\end{array}$ & 2000-2006 & surgery+CRT & PD-1+/CD8+ TILs \\
\hline $\begin{array}{l}\text { Benjamin Goeppert } \\
2013^{8}\end{array}$ & BTC & The University Hospital Heidelberg & 1995-2010 & surgery & $\begin{array}{l}\text { Foxp3 intraepithelial } \\
\text { CD4 intraepithelial }\end{array}$ \\
\hline $\begin{array}{l}\text { Gu Fang-Ming } \\
2012^{10}\end{array}$ & ICC & Zhongshan Hospital & 2000-2006 & surgery & $\begin{array}{l}\text { IL17+ } \\
\text { CD66b+ }\end{array}$ \\
\hline $\begin{array}{l}\text { TARO OSHIKIRI } \\
2003^{12}\end{array}$ & EHBD & $\begin{array}{l}\text { Hokkaido University Hospital or Teine Keijinkai } \\
\text { Hospital or Hokkaido Gastroenterology Hospital }\end{array}$ & 1992-1999 & surgery & CD8+ \\
\hline
\end{tabular}

Table 2. The quality assessment for 5 literatures of immunotherapy by methodological quality (QUADAS-2).

\begin{tabular}{|c|c|c|c|c|c|}
\hline Bias & J.S.Chen & David Malka & Jeeyun Lee & Koichi Shimizu & Seung Tae Kim \\
\hline Random sequence generation (selection bias) & $\hat{z}$ & 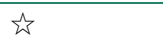 & $\hat{\imath}$ & $\hbar \hat{z}$ & $\check{\imath}$ \\
\hline Allocation concealment (selection bias) & $\grave{z}$ & $\hat{z}$ & $\grave{2}$ & $\hat{t} \boldsymbol{t}$ & $\hat{z}$ \\
\hline Binding of participants and personnel (performance bias) & $\hat{z}$ & $\hat{z}$ & $\hat{\imath}$ & $\hat{y} \bar{y}$ & $\hat{z}$ \\
\hline Binding of outcome assessment (detection bias) & $\hat{z}$ & $\hat{z}$ & $\dot{s}$ & $\hat{x} \hat{z}$ & $\sum$ \\
\hline Incomplete outcome data (attrition bias) & $\grave{z}$ & $\Sigma^{2}$ & $\Sigma$ & $\underline{\psi}$ & 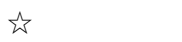 \\
\hline Selective reporting (reporting bias) & 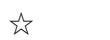 & $i t$ & $\hat{z}$ & $\hat{z}$ &  \\
\hline
\end{tabular}



Table 3. Newcastle Ottawa quality assessment scale for 7 studies.

\begin{tabular}{|c|c|c|c|c|c|c|c|c|}
\hline & & $\begin{array}{l}\text { Ban Seok } \\
\text { Lee }\end{array}$ & $\begin{array}{l}\text { Mariko } \\
\text { Tsukagoshi }\end{array}$ & $\begin{array}{l}\text { Benjamin } \\
\text { Goeppert }\end{array}$ & $\begin{array}{l}\text { Yu Jin } \\
\text { Lim }\end{array}$ & $\begin{array}{l}\text { Benjamin } \\
\text { Goeppert }\end{array}$ & $\begin{array}{l}\text { Gu } \\
\text { Fang-Ming }\end{array}$ & $\begin{array}{l}\text { TARO } \\
\text { OSHIKIRI }\end{array}$ \\
\hline \multicolumn{9}{|l|}{ Selection } \\
\hline \multirow{2}{*}{$\begin{array}{l}\text { Was the case } \\
\text { definition } \\
\text { adequate? }\end{array}$} & Yes, with independent validation & \multirow[t]{2}{*}{$\hat{z}$} & \multirow[t]{2}{*}{ 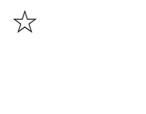 } & \multirow[t]{2}{*}{ 趈 } & \multirow[t]{2}{*}{ 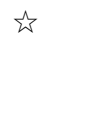 } & \multirow[t]{2}{*}{ 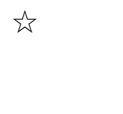 } & \multirow[t]{2}{*}{  } & \multirow[t]{2}{*}{$\hat{z}$} \\
\hline & $\begin{array}{l}\text { Yes, eg record linkage or based on self reports } \\
\text { No description }\end{array}$ & & & & & & & \\
\hline \multirow{2}{*}{$\begin{array}{l}\text { Representativeness } \\
\text { of the cases }\end{array}$} & Consecutive or obviously representative series of cases & \multirow[t]{5}{*}{ 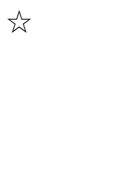 } & \multirow[t]{2}{*}{ 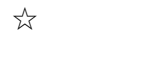 } & \multirow[t]{2}{*}{$\underline{3}$} & \multirow[t]{2}{*}{$\hat{\imath}$} & \multirow[t]{2}{*}{ 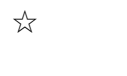 } & \multirow[t]{2}{*}{ 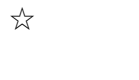 } & \multirow[t]{2}{*}{$i$} \\
\hline & Potential for selection biases or not stated & & & & & & & \\
\hline \multirow{3}{*}{$\begin{array}{l}\text { Selection of } \\
\text { Controls }\end{array}$} & Community controls & & \multirow[t]{3}{*}{$\hat{\imath}$} & & & & & $\dot{s}$ \\
\hline & Hospital controls & & & & & & & \\
\hline & No description & & & & & & & \\
\hline \multirow{2}{*}{$\begin{array}{l}\text { Definition of } \\
\text { controls }\end{array}$} & No history of disease(endpoint) & \multirow[t]{2}{*}{ 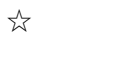 } & \multirow[t]{2}{*}{$\hat{z}$} & \multirow[t]{2}{*}{$\hat{s}$} & \multirow[t]{2}{*}{ 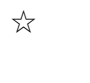 } & \multirow[t]{2}{*}{$\hat{z}$} & \multirow[t]{2}{*}{$\stackrel{s}{3}$} & \multirow[t]{2}{*}{$\hat{z}$} \\
\hline & No description of source & & & & & & & \\
\hline \multicolumn{9}{|l|}{ Comparability } \\
\hline \multirow{2}{*}{$\begin{array}{l}\text { Comparability of } \\
\text { cases and controls } \\
\text { on the basis of the } \\
\text { design or analysis }\end{array}$} & Study controls for (selecting the most important factor) & \multirow[t]{3}{*}{$\hat{\imath}$} & \multirow[t]{3}{*}{ 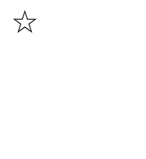 } & \multirow[t]{3}{*}{$\hat{3}$} & 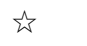 & its & $\hat{\imath}$ & 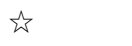 \\
\hline & Study controls for any additional factor & & & & & & & \\
\hline Exposure & & & & & & & & \\
\hline Ascertainment of & Secure record (eg surgical records) & 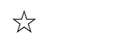 & 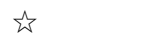 & 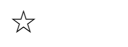 & 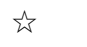 & its &  & 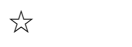 \\
\hline & Structured interview where blind to case/control status & & & & & & & \\
\hline & Interview not blinded to case/control status & & & & & & & \\
\hline & Written self report or medical record only & & & & & & & \\
\hline & No description & & & & & & & \\
\hline Same method of & Yes & $\hat{\imath}$ & 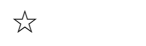 & $\hat{s}$ & $\hat{z}$ & its & $\hat{z}$ & 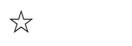 \\
\hline $\begin{array}{l}\text { ascertainment for } \\
\text { cases and controls }\end{array}$ & No & & & & & & & \\
\hline Non-Response rate & Same rate for both groups & & & & & & & \\
\hline & $\begin{array}{l}\text { Non respondents described } \\
\text { Rate different and no designation }\end{array}$ & & & & & & & \\
\hline Score & & 6 & 7 & 6 & 6 & 6 & 6 & 7 \\
\hline
\end{tabular}




\section{Prognostic impact of immune mediators}

In order to evaluate the prognostic effect of immune microenvironment, we performed a meta-analysis on 7 case-control studies to evaluate several immune cells types regarding prognostic factors in BTC.

Immune active factors

For positive immune factors, including intraepithelial tumor-infiltrating $\mathrm{CD} 4+, \mathrm{CD} 8+$, and Foxp3+ T lymphocytes, MHC I and NKG2D, the meta-analysis results revealed that patients with high expression of these factors showed a better OS than those with low expression ( $\mathrm{HR}=0.52$, 95\% $\mathrm{CI}=0.41-0.67, \quad \mathrm{P}<0.00001)$. The Cochran's Q-test resulted in a $P$ value of 0.30 , and the corresponding I2 was $18 \%$, indicating that the degree of variability was basically consistent in each result of study (Figure 2A).

\section{Immune suppressive factors}

On the contrary, the high expression of negative immune factors (CD66b+ neutrophils, Neutrophil-lymphocyte ratio, Intratumoral IL-17+ cells and PD-1+/CD8+ TILs) was significantly associated with poor $\mathrm{OS}(\mathrm{HR}=1.79,95 \% \mathrm{CI}=1.44-2.22$, $\mathrm{P}<0.00001)$. Also, there was no heterogeneity among studies $\left(\mathrm{I}^{2}=0 \%, \mathrm{P}=0.82\right)$ (Figure $\left.2 \mathrm{~B}\right)$.

\section{Immunotherapy targeting tumor microenvironment modulation}

\section{Median PFS and OS}

Information on the median PFS/OS was available for 5 trials. The median PFS for BTC patients who received adjuvant immunotherapy was longer than those who received surgery or chemotherapy alone, and the MD for the five trials demonstrated a highly significant improvement in median PFS for these patients ( $\mathrm{MD}=2.33$; 95\% CI: 0.63-4.02, $\mathrm{P}=0.007$ ). The Cochran's Q-test resulted in a P value of 0.07 and the corresponding I2 was $53 \%$, indicating that there was no significant heterogeneity between studies (Figure 3A).

Besides, the median OS also showed an improvement trend for BTC patients, however, no statistically significant difference was observed in patients with or without adjuvant immunotherapy (MD=1.03; 95\% CI: -1.22-3.29, $\mathrm{P}=0.37$ ). There was also no evidence of heterogeneity among individual studies $(\mathrm{P}=0.12, \mathrm{I} 2=46 \%)$ (Figure $3 \mathrm{~B})$.

PFS/OS at 6, 12 and 18 months

Although there was no significant statistical heterogeneity (PFS: $\mathrm{I}^{2}=18 \%, \mathrm{P}=0.26$; OS: $\mathrm{I}^{2}=0 \%$, $\mathrm{P}=0.70$ ) among the results of included studies, considering the possible presence of clinical heterogeneity, we conducted subgroup analysis to perform meta-analysis according to 6-month, 12-month and 18-month PFS and OS.

A

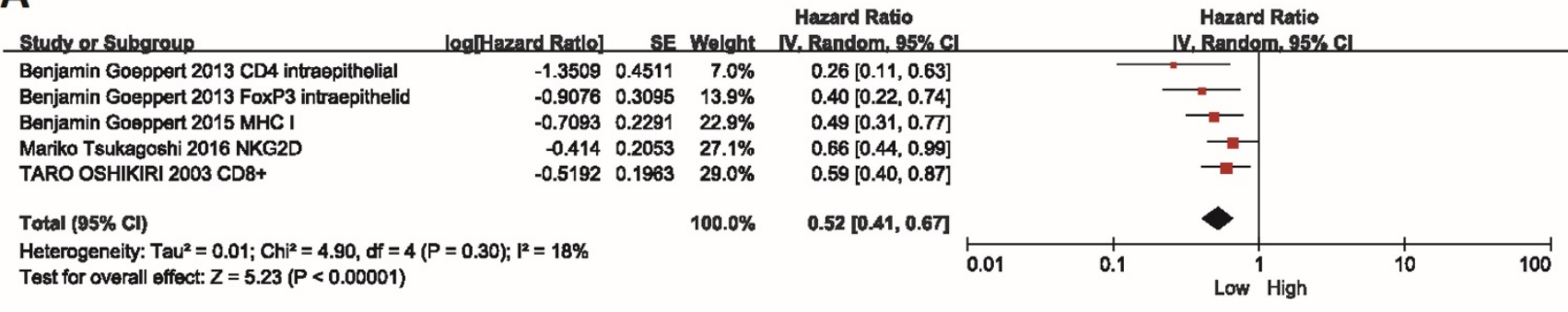

B

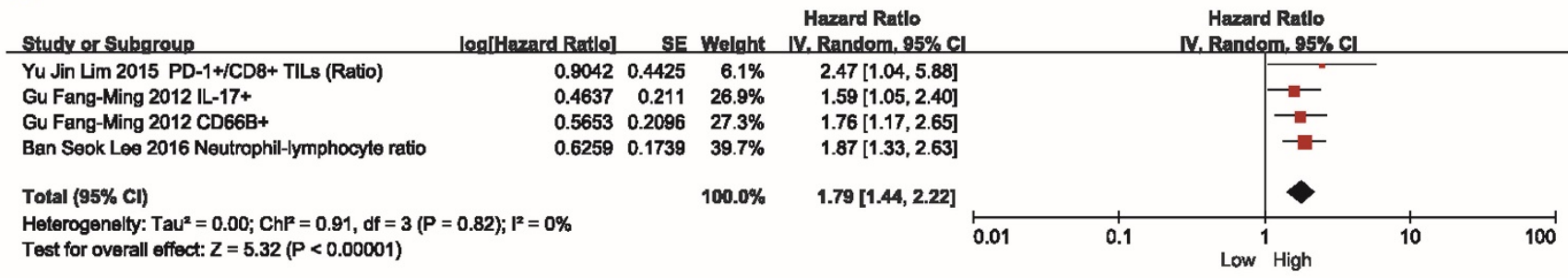

Figure 2. Meta-analysis of the association between immune mediators and prognosis of BTC. Hazard ratio ( $95 \%$ confidence intervals) for the association between immune factors and overall survival of BTC patients has been calculated. (A) Positive immune factors (intraepithelial tumor-infiltrating CD4+, CD8+, and Foxp3+ T lymphocytes, MHC I, NKG2D). (B) Negative immune factors (CD66b+ neutrophils, Neutrophil-lymphocyte ratio, Intratumoral IL-17+ cells and PD-1+/CD8+ TILs). The random effects model (Inverse Variance statistical method, IV) was used. The black diamond gives the overall HR for the combined results of all trials. 




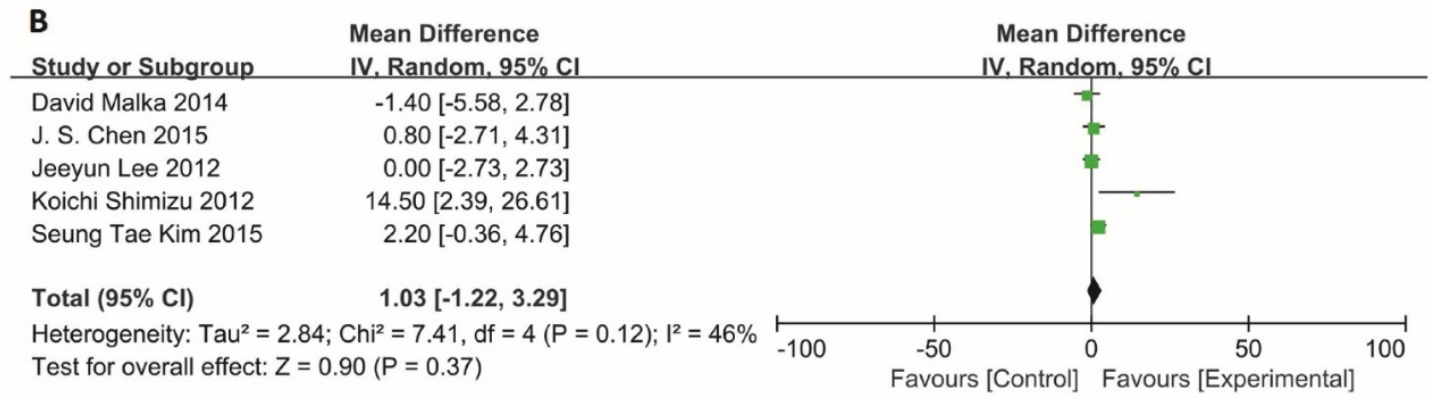

Figure 3. Comparison of median PFS and median OS. Data showed the Mean Difference (MD) and $95 \%$ confidence intervals (CI) for the median PFS and OS between BTC patients who received adjuvant immunotherapy or surgery/chemotherapy alone. Random-effects estimates were used. (A) Analysis of median PFS. (B) Analysis of median OS. The black diamond gives the overall MD for the combined results of all trials.

For total effect, PFS was significantly higher in BTC patients undergoing immunotherapy, compared to patients in control groups $(\mathrm{RR}=1.25 ; 95 \% \mathrm{CI}$ : 1.08-1.46, $\mathrm{P}=0.004)$. The progression-free survival rates were $30.2 \%(324 / 1074)$ for BTC patients in experimental group, in comparison to those in control group $(23.4 \%, 244 / 1041)$.

In subgroup meta-analysis of studies on 6-, 12and 18-month PFS, the 6-month progression-free survival rate was $52.2 \%(187 / 358)$ for BTC patients receiving immunotherapy. In comparison, the 6-month progression-free survival rate was only $41.2 \%(143 / 347)$ in patients receiving surgery or chemotherapy alone. Notably, the estimated pooled risk ratio indicated a highly significant improvement in 6-month PFS for patients who underwent immunotherapy treatment $(\mathrm{RR}=1.23 ; 95 \% \quad \mathrm{CI}$ : 1.05-1.44, $\mathrm{P}=0.009)$. The Cochran's Q-test resulted in a $\mathrm{P}$ value of 0.61 , and the corresponding $\mathrm{I}^{2}$ was $0 \%$, indicating that the degree of variability was basically consistent in each result of study (Figure 4A).

Information on 6-, 12-, 18-months OS was available for 4 trials including 636 patients. For total effect, overall survival was significantly higher in BTC patients undergoing immunotherapy, compared to patients in control groups (RR=1.16; 95\% CI: 1.07-1.27, $\mathrm{P}=0.0006)$. The survival rate reached 52.2\% (349/669) for BTC patients in experimental group. In comparison, it reached only $44.7 \%(287 / 642)$ in patients in control groups (Figure 4B). Besides, the 6-month survival rate was significantly raised with a value of $81.6 \%(182 / 223)$ for BTC patients who were enrolled in experimental group. In comparison, 6-month survival rate was $68.7 \%(147 / 214)$ in control group. The estimated RR was 1.17 (95\% CI: 1.06-1.30, $\mathrm{P}=0.002)$. The Cochran's $\mathrm{Q}$ test for these data resulted in a $P$ value of 0.77 , and the corresponding $\mathrm{I}^{2}$ was $0 \%$ (Figure 4B). Additionally, publication bias was assessed with Egger's test and funnel plots (Figure 5), indicating that there were no significant bias among these studies $(\mathrm{P}>0.05)$.

\section{Discussion}

Our meta-analysis combined the outcomes of 2339 biliary tract cancer patients from 12 individual studies, confirming that immune microenvironment was related to the prognosis of BTC and immunotherapy by modulating the tumor microenvironment were feasible treatments that can improve median progression free survival, 6-month PFS and 6-month OS combined with surgery or chemotherapy for BTC.

The human immune responses against tumor are mainly dependent on the cellular immunity. Tumor cells are often surrounded by infiltrating inflammatory cells, particularly lymphocytes and macrophages [27]. Current studies found that the successful response of immune checkpoint blockade was basically depended on the sufficient $\mathrm{T}$ cell infiltration. And immune mediators in tumor microenvironment were crucial for tumor infiltrating lymphocytes infiltration [28]. Therefore, we performed a systematic meta-analysis on immune factors and their effect on prognosis. 
A

Study or Subgroup Events Total Events Total Weight M-H. Random. 95\% Cl 6 months

David Malka 2014

J. S. Chen 2015

Jeeyun Lee 2012

$\begin{array}{rrrrr}39 & 76 & 33 & 74 & 13.6 \% \\ 32 & 62 & 23 & 60 & 10.6 \% \\ 64 & 135 & 52 & 133 & 17.2 \% \\ 25 & 36 & 17 & 26 & 12.7 \% \\ 27 & 49 & 18 & 54 & 8.8 \% \\ & 358 & & 347 & 62.8 \%\end{array}$

Koichi Shimizu 2012

Seung Tae Kim 2015

Subtotal $(95 \% \mathrm{Cl})$ 143

$1.15[0.82,1.61]$

$1.35[0.90,2.01]$

$1.21[0.92,1.60]$

$1.06[0.75,1.51]$

$1.65[1.05,2.60]$

$1.23[1.05,1.44]$

Heterogeneity: $\mathrm{Tau}^{2}=0.00 ; \mathrm{Chi}^{2}=2.69, \mathrm{df}=4(\mathrm{P}=0.61) ; \mathrm{I}^{2}=0 \%$

Test for overall effect: $Z=2.61(P=0.009)$

12 months

David Malka 2014

J. S. Chen 2015

Jeeyun Lee 2012

Koichi Shimizu 2012

Seung Tae Kim 2015

Subtotal $(95 \% \mathrm{CI})$

Total events

$\begin{array}{lllll}12 & 76 & 20 & 74 & 4.9 \%\end{array}$

$\begin{array}{llll}135 & 22 & 133 & 7.7 \%\end{array}$

$\begin{array}{lll}10 & 26 & 6.8 \%\end{array}$ Test for overall effect: $Z=1.13(P=0.26)$

18 months

David Malka 2014

J. S. Chen 2015

Jeeyun Lee 2012

Koichi Shimizu 2012

Seung Tae Kim 2015

Subtotal $(95 \% \mathrm{Cl})$

Total events

$\begin{array}{rr}3 & 76 \\ 1 & 62 \\ 25 & 135 \\ 20 & 36 \\ 2 & 49 \\ & 358\end{array}$

$\begin{array}{lll}7 & 54 & 2.5 \%\end{array}$

$(P=0.05) ;\left.\right|^{2}=58 \%$

4]

$0.58[0.31,1.11]$

$3.23[0.93,11.15]$

$1.39[0.85,2.27]$

$1.81[1.06,3.07]$

$1.26[0.49,3.22]$

$1.32[0.81,2.14]$

Heterogeneity: $\mathrm{Tau}^{2}=0.05 ; \mathrm{Chi}^{2}=4.75, \mathrm{df}=4(\mathrm{P}=0.31) ; \mathrm{l}^{2}=16 \%$ Test for overall effect: $Z=0.77(P=0.44)$

$\begin{array}{llllll}\text { Total }(95 \% \mathrm{Cl}) & & 1074 & & 1041 & 100.0 \% \\ \text { Total events } & 324 & & 244 & \end{array}$

Heterogeneity: $\mathrm{Tau}^{2}=0.01 ; \mathrm{Chi}^{2}=17.02, \mathrm{df}=14(\mathrm{P}=0.26) ; \mathrm{I}^{2}=18 \%$

Test for overall effect: $Z=2.92(P=0.004)$

Test for subaroun differences: $\mathrm{Chi}^{2}=0.09 . \mathrm{df}=2(\mathrm{P}=0.95) . \mathrm{I}^{2}=0 \%$

$0.58[0.14,2.36]$

$0.48[0.05,5.20]$

$1.30[0.75,2.24]$

$1.81[0.95,3.45]$

$0.44[0.09,2.17]$

$1.20[0.76,1.89]$

H. Random, $95 \%$ C

Experimental Control

Study or Subgroup Events Total Events Total Weight M-H. Random. $95 \% \mathrm{Cl}$ 6 months

David Malka 2014

J. S. Chen 2015

Koichi Shimizu 2012

Seung Tae Kim 2015

Subtotal $(95 \% \mathrm{Cl})$

Total events

Heterogeneity: $\mathrm{Tau}^{2}=0.00 ; \mathrm{Chi}^{2}=1.11, \mathrm{df}=3(\mathrm{P}=0.77) ; \mathrm{I}^{2}=0 \%$

Test for overall effect: $Z=3.08(P=0.002)$

12 months

David Malka 2014

J. S. Chen 2015

Koichi Shimizu 2012

Seung Tae Kim 2015

Subtotal $(95 \% \mathrm{Cl})$

Total events

$\begin{array}{lllll}62 & 76 & 52 & 74 & 21.9 \%\end{array}$

$\begin{array}{lllll}46 & 62 & 41 & 60 & 14.3 \%\end{array}$

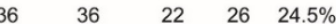

$\begin{array}{llll}36 & 22 & 26 & 24.5 \% \\ 49 & 32 & 54 & 10.2 \%\end{array}$

$\begin{array}{rrr}32 & 54 & 10.2 \% \\ & 214 & \mathbf{7 0 . 9} \%\end{array}$

$1.16[0.97,1.39]$

$1.18[1.00,1.41]$

$1.31[1.00,1.71]$

$1.17[1.06,1.30]$

作

Test for overall effect: $Z=1.43(P=0.15)$

1.12.3 18 months

David Malka 2014

J. S. Chen 2015

Koichi Shimizu 2012

Seung Tae Kim 2015

Subtotal $(95 \% \mathrm{Cl})$

Total events

$\begin{array}{lllll}35 & 76 & 38 & 74 & 6.7 \%\end{array}$

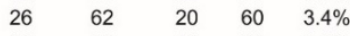

$\begin{array}{llll}36 & 18 & 26 & 9.3 \%\end{array}$

$\begin{array}{llll}49 & 16 & 54 & 2.5 \%\end{array}$

92

$0.90[0.65,1.25]$
$1.26[0.79,2.00]$
$1.28[0.97,1.70]$
$1.31[0.76,2.25]$
$\mathbf{1 . 1 5}[0.95,1.39]$

Heterogeneity: $\mathrm{Tau}^{2}=0.02 ; \mathrm{Chi}^{2}=3.61, \mathrm{df}=3(\mathrm{P}=0.31) ; \mathrm{I}^{2}=17 \%$

Test for overall effect: $Z=0.38(P=0.70)$

Total $(95 \% \mathrm{Cl})$

Total events

349

$\begin{array}{llll}76 & 19 & 74 & 2.1 \%\end{array}$

$\begin{array}{rrrrr}7 & 62 & 7 & 60 & 0.8 \% \\ 25 & 36 & 12 & 26 & 3.3 \%\end{array}$

$0.77[0.42,1.40]$

$0.97[0.36,2.59]$

$1.50[0.94,2.40]$

$0.88[0.38,2.05]$

$1.07[0.75,1.54]$

Heterogeneity: $\mathrm{Tau}^{2}=0.00 ; \mathrm{Chi}^{2}=8.20, \mathrm{df}=11(\mathrm{P}=0.70) ; \mathrm{l}^{2}=0 \%$

Test for overall effect: $Z=3.44(P=0.0006)$

Test for subaroun differences: $\mathrm{Chi}^{2}=0.23 . \mathrm{df}=2(\mathrm{P}=0.89) . \mathrm{I}^{2}=0 \%$

$1.16[1.07,1.27]$



Figure 4. Subgroup analysis of 6, 12, 18-month PFS and OS. Random effects model (Mantel-Haenszel method) was used here. Each trial is represented by a square, the center of which gives the risk ratio (RR) for that trial. The black diamond gives the overall RR for the combined results of all trials. The Cochran's $Q$ test (Chi2) was applied to evaluate whether the results of the studies were homogeneous. All the heterogeneity was evaluated by inconsistency index $\left(I^{2}\right)$. The overall effect was estimated by $P$-value. A p-value of less than 0.05 is considered to be statistically significant. Subgroup analysis was performed to this meta-analysis according to 6-month, 12-month and 18-month. (A) Analysis of 6-, 12- and 18-month PFS. (B) Analysis of 6-, 12- and 18-month OS. 
A

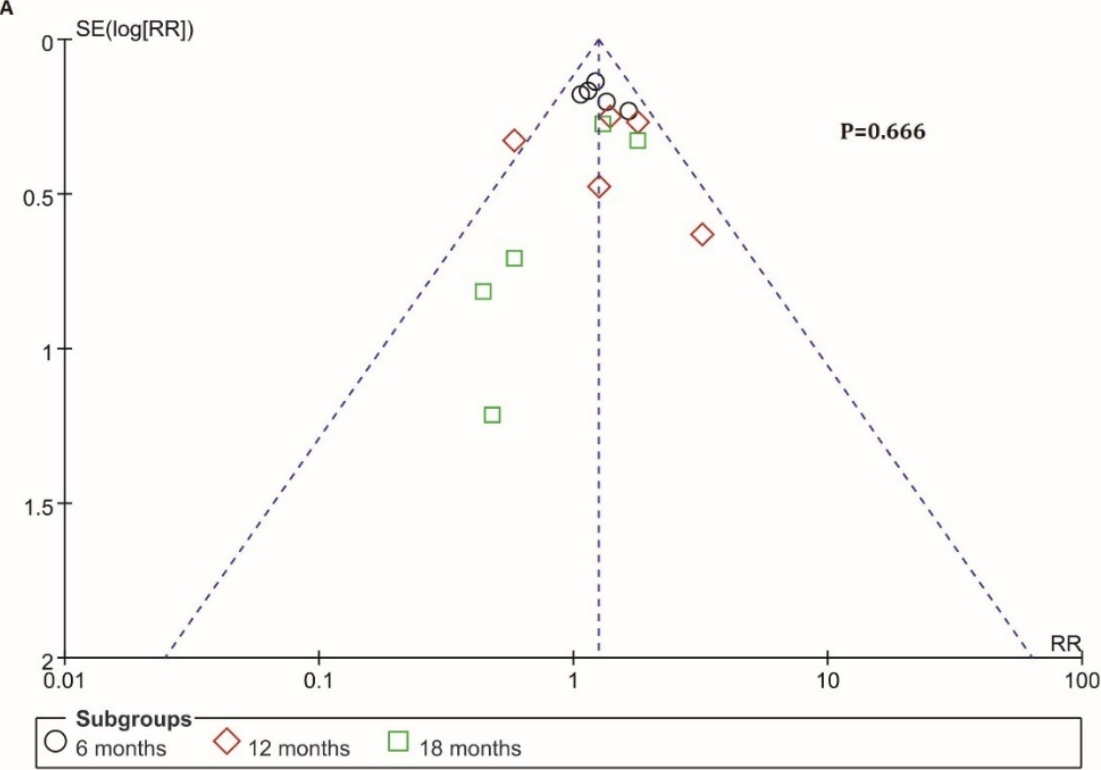

B

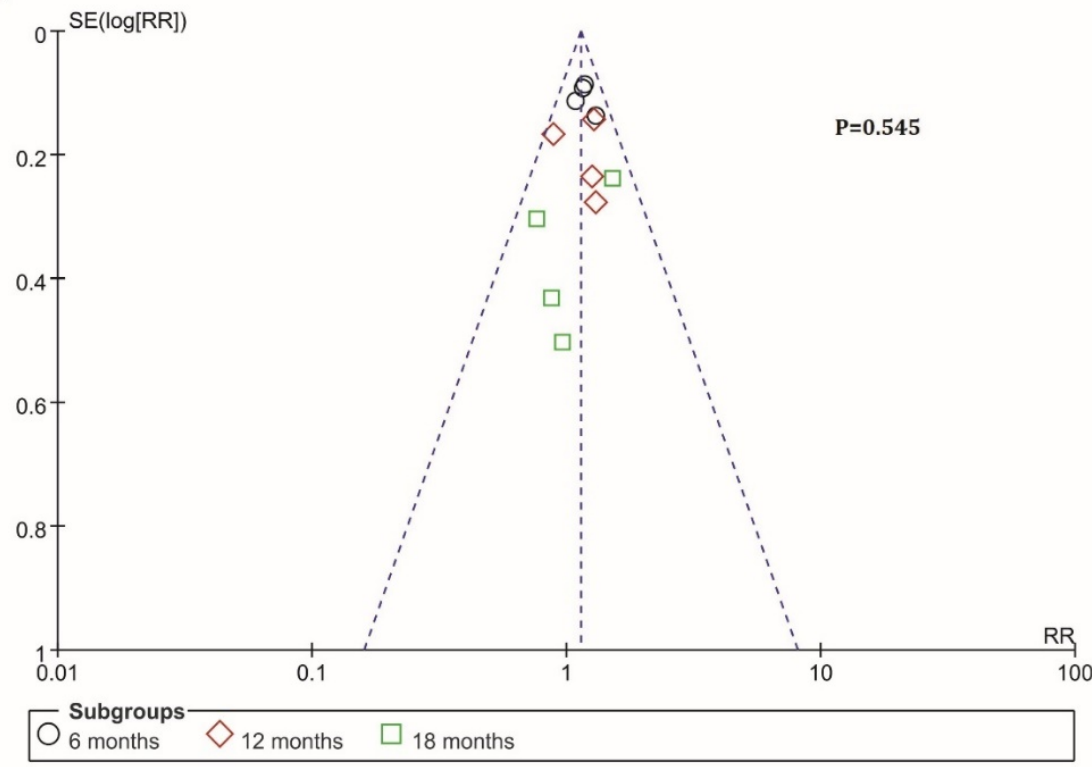

Figure 5. Funnel plots of PFS and OS. Publication bias was assessed by the funnel plots. The X-axis was risk ratio (RR), and the $y$-axis represents the standard error (SE, log risk ratio). No publication bias was found using Egger's test $(P=0.666, P=0.545)$ via $R$ platform. Each study was divided into three sub-groups which represented by a different type of dot (black circle: 6-month, red diamond: 12-month, green square: 18-month). (A) Analysis of 6-, 12- and 18-month PFS. (B) Analysis of 6-, 12- and 18-month OS.

The 7 case-control series confirmed that the high level of CD66b+ neutrophils, Neutrophil-lymphocyte ratio, Intratumoral IL-17+ cells and PD-1+/CD8+ TILs were associated with a poor prognosis in BTC. The elevated Neutrophils cells and reduced CD8+ lymphocyte demonstrated an exhausted state of the effector T cells, thus contributing to a progression of tumors [10, 13, 14, 29]. In comparison, intraepithelial tumor-infiltrating CD4+, CD8+, and Foxp3+ T lymphocytes, MHC I and NKG2D were referred as positive factors to prolong the overall survival of patients with BTC. The role of intraepithelial tumor-infiltrating CD8+ T lymphocytes, MHC I and
NKG2D has been identified and reported a beneficial prognostic effect of high cell counts in a variety of human malignancies including BTC $[8,9,11,12,27$, 30-32]. Goepport also found a better prognostic impact of both intraepithelial tumor-infiltrating CD4+ and Foxp3+ $\mathrm{T}$ lymphocytes. However, the role of these two immune mediators in immunologic anti-tumor response is more controversial in different types of cancers [33-39]. In this BTC meta-analysis, both intraepithelial tumor-infiltrating $\mathrm{CD} 4+$ and Foxp3+ T lymphocytes were associated with a longer survival. This meta-analysis indicated that immune microenvironment was related to the prognosis of 
BTC. The outcomes revealed the statistical significance in our meta-analysis related to prognosis of immune mediators.

A further observation of immunotherapy targeting tumor microenvironment modulation showed a significant survival benefit with regard to the median and 6-month PFS $(\mathrm{P}<0.05)$ but not to the 12- and 18-month PFS ( $\mathrm{P}>0.05)$ when patients received immunotherapy. The total effect and 6-month OS was also significantly improved, even though the median, 12- and 18-month overall survival showed no significant affected in patients with or without adjuvant immunotherapy treatment.

There are two possible causes involved in showing no statistical significance concerning the result of 12-, and 18-month PFS and OS. One reason is that 4 out of 5 articles focused on passive treatment regimens. The addition of Cetuximab to chemotherapy showed an improvement on the median PFS in BTC, and a trend of median OS improvement was observed. The intratumoral heterogeneity in patients could lead to the resistant affects in clinical curative and the difficulty in a target for passive treatment regimens. There have been reported that the intratumoral heterogeneity in EGFR mutation status had recently been described and ranged from $13.9 \%$ to $27 \%$ in some studies [40, 41]. Also, David Malka study [17] is the first and the only to assess the activity of chemotherapy with or without Cetuximab in non-Asian patients with BTC. Moreover, four out of five studies have centered on passive treatment regimens combined with chemotherapy [17, 18, 21], and one article concerned about active treatment regimens [23]. The different types of cellular immunity could be the other reason. It is well known that tumor could escape the host immune surveillance and is tough to cure. There were different types of immune cells affected the cure of tumors.

Some limitations in our study need to be considered carefully. First, the total sample size is not very large, and several researches did not provide sufficiently long follow-up time. One study did not report the overall survival time. Second, heterogeneity is a potential issue that may affect the interpretation of the results of all meta-analyses. The presence of heterogeneity may result from many other factors, including age distribution, gender, regimens, and vaccine types.

\section{Conclusion}

Overall, our analysis demonstrated that the level of immune mediators could be a predicative factor for prognosis of BTC patients, and it turned out that immunotherapy regimens for tumor microenvironment modulation could significantly prolong the median PFS, 6-month PFS and 6-month OS so as to improve the quality of life for patients. Further researches will be in demand, to attempt to exposit the influence of treatment regimens for immune mediators exerts on OS, about immune cells or mediators in tumor microenvironment.

\section{Abbreviations}

BTC: biliary tract cancer; EGFR: growth factor receptor; VEGF: vascular endothelial growth factor; PPV: personalized peptide vaccine; CD66b: neutrophil recruitment; NKG2D: natural killer group 2 member D; NLR: neutrophil-to-lymphocyte ratio; QUADAS-2: quality assessment of diagnostic accuracy studies-2; NOS: newcastle ottawa quality assessment scale; PFS: progression free survival; OS: overall survival; MD: mean difference; RR: risk ratio; CI: confidence intervals; HR: hazard ratio; $\mathrm{I}^{2}$ : inconsistency index.

\section{Acknowledgements}

This work was supported by National Science Fund Projects $(81672997,31601075)$ and the Capacity Building Project of Shanghai Engineering Research Center (16DZ2281000).

\section{Authors' contributions}

Ying Wang, Min Ding and Qian Zhang designed the pipeline of the analysis, searched and extracted the literatures, performed the statistical analysis and drafted the manuscript. Jinghan Wang, Xijing Yang and Fuping Zhou and evaluated the inconsistent literatures. Linfang Li, Zhengang Yuan and Huajun Jin revised the manuscript. Qijun Qian conceived and coordinated the overall study and revised the manuscript. All authors read and approved the final manuscript.

\section{Competing interests} interests.

The authors declare that they have no competing

\section{References}

1. Ciombor KK, Goff LW. Advances in the management of biliary tract cancers. Clinical advances in hematology \& oncology. 2013; 11(1):28-34.

2. Noel MS, Hezel AF. New and emerging treatment options for biliary tract cancer. OncoTargets and therapy. 2013; 6:1545-1552.

3. Patel T. Cholangiocarcinoma-controversies and challenges. Nature reviews Gastroenterology \& hepatology. 2011; 8(4):189-200.

4. Randi G, Malvezzi M, Levi F, et al. Epidemiology of biliary tract cancers: an update. Annals of oncology. 2009; 20(1):146-159.

5. Yang R, Wang B, Chen YJ, et al. Efficacy of gemcitabine plus platinum agents for biliary tract cancers: a meta-analysis. Anti-cancer drugs. 2013; 24(8):871-877.

6. Hezel AF, Zhu AX. Systemic therapy for biliary tract cancers. The oncologist. 2008; 13(4):415-423.

7. Glimelius B, Hoffman K, Sjoden PO, et al. Chemotherapy improves survival and quality of life in advanced pancreatic and biliary cancer. Annals of oncology. 1996; 7(6):593-600. 
8. Goeppert B, Frauenschuh L, Zucknick M, et al. Prognostic impact of tumour-infiltrating immune cells on biliary tract cancer. British journal of cancer. 2013; 109(10):2665-2674.

9. Goeppert B, Frauenschuh L, Zucknick M, et al. Major histocompatibility complex class I expression impacts on patient survival and type and density of immune cells in biliary tract cancer. British journal of cancer. 2015; 113(9):1343-1349.

10. Gu FM, Gao Q, Shi GM, et al. Intratumoral IL-17(+) cells and neutrophils show strong prognostic significance in intrahepatic cholangiocarcinoma. Annals of surgical oncology. 2012; 19(8):2506-2514.

11. Tsukagoshi M, Wada S, Yokobori T, et al. Overexpression of natural killer group 2 member $\mathrm{D}$ ligands predicts favorable prognosis in cholangiocarcinoma. Cancer science. 2016; 107(2):116-122.

12. Oshikiri $T$, Miyamoto $M$, Shichinohe $T$, et al. Prognostic value of intratumoral CD8+ T lymphocyte in extrahepatic bile duct carcinoma as essential immune response. Journal of surgical oncology. 2003; 84(4):224-228.

13. Lim YJ, Koh J, Kim K, et al. High ratio of programmed cell death protein 1 $(\mathrm{PD}-1)(+) / \mathrm{CD} 8(+)$ tumor-infiltrating lymphocytes identifies a poor prognostic subset of extrahepatic bile duct cancer undergoing surgery plus adjuvant chemoradiotherapy. Radiotherapy and oncology. 2015; 117(1):165-170.

14. Lee BS, Lee SH, Son JH, et al. Neutrophil-lymphocyte ratio predicts survival in patients with advanced cholangiocarcinoma on chemotherapy. Cancer immunology immunotherapy. 2016; 65(2):141-150.

15. Takahashi R, Yoshitomi M, Yutani S, et al. Current status of immunotherapy for the treatment of biliary tract cancer. Human vaccines \& immunotherapeutics. 2013; 9(5):1069-1072.

16. Muller BG, De Aretxabala X, Gonzalez Domingo M: A review of recent data in the treatment of gallbladder cancer: what we know, what we do, and what should be done. American Society of Clinical Oncology educational book / ASCO American Society of Clinical Oncology Meeting. 2014; e165-170.

17. Malka $D$, Cervera $P$, Foulon $S$, et al Gemcitabine and oxaliplatin with or without cetuximab in advanced biliary-tract cancer (BINGO): a randomised, open-label, non-comparative phase 2 trial. The Lancet Oncology. 2014; 15(8):819-828.

18. Chen JS, Hsu C, Chiang NJ, et al. A KRAS mutation status-stratified randomized phase II trial of gemcitabine and oxaliplatin alone or in combination with cetuximab in advanced biliary tract cancer. Annals of oncology. 2015; 26(5):943-949.

19. Guion-Dusserre JF, Lorgis V, Vincent J, et al. FOLFIRI plus bevacizumab as a second-line therapy for metastatic intrahepatic cholangiocarcinoma. World journal of gastroenterology. 2015; 21(7):2096-2101.

20. Kim ST, Jang KT, Lee SJ, et al. Tumour shrinkage at 6 weeks predicts favorable clinical outcomes in a phase III study of gemcitabine and oxaliplatin with or without erlotinib for advanced biliary tract cancer. BMC cancer. 2015; 15:530.

21. Lee J, Park SH, Chang HM, et al. Gemcitabine and oxaliplatin with or without erlotinib in advanced biliary-tract cancer: a multicentre, open-label, randomised, phase 3 study. The Lancet Oncology. 2012; 13(2):181-188.

22. Marks EI, Yee NS. Immunotherapeutic approaches in biliary tract carcinoma: Current status and emerging strategies. World journal of gastrointestinal oncology. 2015; 7(11):338-346

23. Shimizu K, Kotera Y, Aruga A, et al. Clinical utilization of postoperative dendritic cell vaccine plus activated T-cell transfer in patients with intrahepatic cholangiocarcinoma. Journal of hepato-biliary-pancreatic sciences. 2012; 19(2):171-178.

24. Whiting PF, Rutjes AW, Westwood ME, et al. OUADAS-2: a revised tool for the quality assessment of diagnostic accuracy studies. Annals of internal medicine. 2011; 155(8):529-536.

25. Stang A. Critical evaluation of the Newcastle-Ottawa scale for the assessment of the quality of nonrandomized studies in meta-analyses. European journal of epidemiology. 2010; 25(9):603-605.

26. [No authors listed]. Computer program; Review Manager (RevMan) Version 5.3. Copenhagen: The Nordic Cochrane Centre. The Cochrane Collaboration. 2014.

27. Mahmoud SM, Paish EC, Powe DG, et al. Tumor-infiltrating CD8+ lymphocytes predict clinical outcome in breast cancer. Journal of clinical oncology. 2011; 29(15): 1949-1955.

28. Tang H, Wang Y, Chlewicki LK, et al. Facilitating T Cell Infiltration in Tumor Microenvironment Overcomes Resistance to PD-L1 Blockade. Cancer cell. 2016; 29(3):285-296.

29. Kusumanto YH, Dam WA, Hospers GA, et al. Platelets and granulocytes, in particular the neutrophils, form important compartments for circulating vascular endothelial growth factor. Angiogenesis. 2003; 6(4):283-287.

30. Mlecnik B, Tosolini M, Kirilovsky A, et al. Histopathologic-based prognostic factors of colorectal cancers are associated with the state of the local immune reaction. Journal of clinical oncology. 2011; 29(6):610-618.

31. Galon J, Costes A, Sanchez-Cabo F, et al. Type, density, and location of immune cells within human colorectal tumors predict clinical outcome. Science. 2006; 313 (5795): 1960-1964.

32. Fukunaga A, Miyamoto $\mathrm{M}$, Cho $\mathrm{Y}$, et al. CD8+ tumor-infiltrating lymphocytes together with CD4+ tumor-infiltrating lymphocytes and dendritic cells improve the prognosis of patients with pancreatic adenocarcinoma. Pancreas. 2004; 28(1):e26-31.

33. Yoon HH, Orrock JM, Foster NR, et al. Prognostic impact of FoxP3+ regulatory $\mathrm{T}$ cells in relation to CD8+ T lymphocyte density in human colon carcinomas. PloS one. 2012; 7(8):e42274.
34. Mathai AM, Kapadia MJ, Alexander J, et al. Role of Foxp3-positive tumor-infiltrating lymphocytes in the histologic features and clinical outcomes of hepatocellular carcinoma. The American journal of surgical pathology. 2012; 36(7):980-986.

35. Sinicrope FA, Rego RL, Ansell SM, et al. Intraepithelial effector $(\mathrm{CD} 3+)$ /regulatory (FoxP3+) T-cell ratio predicts a clinical outcome of human colon carcinoma. Gastroenterology. 2009; 137(4): 1270-1279.

36. Siddiqui SA, Frigola $X$, Bonne-Annee $S$, et al. Tumor-infiltrating Foxp3-CD4+CD25+ T cells predict poor survival in renal cell carcinoma. Clinical cancer research. 2007; 13(7):2075-2081.

37. Cho Y, Miyamoto M, Kato K, et al. CD4+ and CD8+ $\mathrm{T}$ cells cooperate to improve prognosis of patients with esophageal squamous cell carcinoma. Cancer research. 2003; 63(7):1555-1559.

38. Diederichsen AC, Hjelmborg J, Christensen PB, et al. Prognostic value of the CD4+/CD8+ ratio of tumour infiltrating lymphocytes in colorectal cancer and HLA-DR expression on tumour cells. Cancer immunology immunotherapy. 2003; 52(7):423-428.

39. Waldner M, Schimanski CC, Neurath MF. Colon cancer and the immune system: the role of tumor invading T cells. World journal of gastroenterology. 2006; 12(45):7233-7238

40. Luo YH, Chen YM. Influence of chemotherapy on EGFR mutation status. Translational lung cancer research. 2013; 2(6):442-444.

41. Lv ZC, Ning JY, Chen HB. Efficacy and toxicity of adding cetuximab to chemotherapy in the treatment of metastatic colorectal cancer: a meta-analysis from 12 randomized controlled trials. Tumour biology. 2014; 35(12):11741-11750. 